\title{
MicroRNA let-7g inhibits angiotensin II-induced endothelial senescence via the LOX-1-independent mechanism
}

\author{
PO-YUAN HSU ${ }^{1}$, WEN-YI LIN ${ }^{2,3}$, RUEY-TAY LIN ${ }^{4}$ and SUH-HANG H. JUO ${ }^{1,5-8}$ \\ ${ }^{1}$ Department of Medical Research, China Medical University Hospital, Taichung 40402; \\ ${ }^{2}$ Department of Occupational Medicine, Kaohsiung Municipal Hsiaokang Hospital; ${ }^{3}$ Hepatobiliary Division, \\ Department of Internal Medicine and ${ }^{4}$ Department of Neurology, Kaohsiung Medical University Hospital, Kaohsiung 80708; \\ ${ }^{5}$ Graduate Institute of Biomedical Sciences, China Medical University; ${ }^{6}$ Institute of New Drug Development, \\ College of Biopharmaceutical and Food Sciences, China Medical University; ${ }^{7}$ Brain Disease Research Center, \\ China Medical University; ${ }^{8}$ Center for Myopia and Eye Disease, Department of Medical Research, \\ China Medical University Hospital, Taichung 40402, Taiwan R.O.C.
}

Received May 11, 2017; Accepted December 15, 2017

DOI: $10.3892 /$ ijmm.2018.3416

\begin{abstract}
Endothelial senescence leads to cell dysfunction, which in turn eventually results in cardiovascular disease. Identifying factors that regulate endothelial senescence may provide insight into the pathogenesis of aging. Insulin-like growth factor (IGF) signaling has a significant role in the physiology of endothelial cells (ECs). Overactivation of IGF signaling has been implicated in promoting the aging process. Lectin-like oxidized low-density lipoprotein (oxLDL) receptor-1 (LOX-1) is a scavenger receptor that mediates the internalization of oxLDL into cells. Previous studies by our group have indicated that microRNA let-7g exerts an anti-aging effect on ECs and also suppresses LOX-1 expression. Since LOX-1 also induces the aging process, the present study we explored whether let-7g still exerts an anti-aging effect on ECs when LOX-1 is suppressed. Angiotensin II (Ang II) was used to induce senescence in ECs. It was revealed that Ang II significantly increased the expression of aging markers, including $\beta$-galactosidase, LOX-1, IGF1 and its receptor IGF1R. On the contrary, Ang II decreased the expression of the anti-aging gene sirtuin 1 (SIRT1). When LOX-1 was knocked down by small interfering RNA, let-7g still dose-dependently decreased the expression of $\beta$-galactosidase ( $\beta$-gal), LOX-1, IGF1 and IGF1R, and SIRT1 was still upregulated. Using senescence-associated $\beta$-gal staining, it was confirmed that
\end{abstract}

Correspondence to: Dr Suh-Hang H. Juo, Department of Medical Research, China Medical University Hospital, 91 Hsueh-Shih Road, Taichung 40402, Taiwan R.O.C.

E-mail: hjuo@mail.cmu.edu.tw

Key words: microRNA let-7g, lectin-like oxidized low-density lipoprotein receptor-1, cell senescence, angiotensin II, human umbilical vein endothelial cells, insulin-like growth factor let-7g exerts a LOX-1-independent anti-aging effect on ECs. In conclusion, the present study demonstrated that let-7g has an anti-aging effect regardless of the presence or absence of LOX-1.

\section{Introduction}

Senescence may be caused by telomere uncapping due to replicative exhaustion, mitochondrial deterioration, oxidative stress, severe or irreparable DNA damage or selected oncogene expression (1). Endothelial senescence leads to cell dysfunction, which in turn eventually results in cardiovascular diseases, including hypertension and atherosclerosis (2). Oxidized low-density lipoprotein (oxLDL) is an important risk factor in promoting the development of atherosclerosis. oxLDL stimulates endothelial cells (ECs) to produce adhesion molecules and proinflammatory substances. The scavenger receptor lectin-like oxLDL receptor-1 (LOX-1) mediates the binding and internalization of oxLDL into cells. Accordingly, LOX-1 has a critical role in endothelial dysfunction (3), and LOX-1 has been suggested to be an aging marker (4).

Angiotensin II (Ang II) is the primary effector of the renin-angiotensin system (RAS) and is a multifunctional hormone that has a major role in regulating blood pressure and cardiovascular homeostasis (5). Mammalian cells express 2 types of Ang II receptors, Ang II type 1 receptor (AT1R) and AT2R (6,7). Ang II-induced reactive oxygen species production via AT1R promotes the onset of vascular senescence as well as functional and structural changes in blood vessels (8). Ang II signaling is considered to contribute to the pathogenesis of atherosclerosis (9). In addition, Ang II has been reported to upregulate LOX-1, which facilitates oxLDL uptake by ECs (10). However, it remains elusive whether Ang II also deteriorates EC function via a LOX-1-independent pathway.

Sirtuin 1 (SIRT1) is implicated in anti-aging processes and has a role in the tolerance of oxidative stress (11). A previous study by our group demonstrated that micro (mi)RNA let- $7 \mathrm{~g}$ increased SIRT1 expression in ECs (12). SIRT1 is highly 
expressed in blood vessels, and a decrease of SIRT1 expression may be a risk factor for atherosclerosis (13-15). The insulin-like growth factor 1 (IGF1) signal transduction pathway has been demonstrated to be associated with the aging process $(16,17)$. Furthermore, SIRT1 expression has been negatively correlated with the level of IGF1 (18). SIRT1 has been linked to the insulin/IGF signaling pathway in Caenorhabditis elegans, drosophila and mice through its ability to deacetylate forkhead box O proteins (19-21). Treatment of cells with IGF1 may decrease their SIRT1 levels, suggesting an inverse association between SIRT1 and the insulin/IGF pathway (20).

MicroRNAs (miRNAs) are small non-coding RNAs that regulate gene expression through degradation or translational inhibition of targeted mRNA (22). The miRNA let-7 family has a pivotal role in cell proliferation, cancer and cardiovascular diseases $(23,24)$. A previous study by our group reported that let-7g directly targets and suppresses LOX-1 (25). Further studies by our group have reported that let-7g improves several endothelial functions by causing a decrease of senescence, inflammation and monocyte adhesion, and an increase of angiogenesis $(12,25,26)$. The present study aimed to investigate whether let- $7 \mathrm{~g}$ also provides endothelial protection via a LOX-1-independent mechanism. Let-7g was tested for its anti-aging effect against Ang II-induced senescence in ECs while LOX-1 was suppressed.

\section{Materials and methods}

Cell culture and treatment. Human umbilical vein endothelial cells (HUVECs) were purchased as pooled primary cells from Lonza (Basel, Switzerland). The HUVECs were cultured at $37^{\circ} \mathrm{C}$ in an atmosphere of $5 \% \mathrm{CO}_{2}$ in Clonetics Endothelial Cell Growth Media (EBM) supplemented with the BulletKit containing bovine brain extract, epidermal growth factor, hydrocortisone, gentamicin, amphotericin B, fetal bovine serum (FBS) and ascorbic acid according to the manufacturer's instructions (Lonza).

Prior to each experiment, the cells at passage 3-5 were starved in an EGM-2 medium (EBM medium with supplement) containing $0.5 \% \mathrm{FBS}$ for $24 \mathrm{~h}$ to synchronize the cells in G0 phase.

Since Ang II at $10^{3} \mathrm{nM}$ was reported to increase HUVEC proliferation (27), Ang II (Sigma-Aldrich; Merck KGaA, Darmstadt, Germany) at $10-10^{4} \mathrm{nM}$ was initially applied to HUVECs for $24 \mathrm{~h}$ to determine the optimal dose for subsequent experiments.

Transfection of LOX-1 small-interfering (si)RNA. The HUVECs were synchronized via starvation for $24 \mathrm{~h}$ prior to each experiment. After they were arrested, the HUVECs were treated with culture media containing Ang II $\left(10^{4} \mathrm{nM}\right)$ for 24 h. LOX-1 siRNA (25, 50 and 100 nM; cat. no. NM_002543) or control siRNA (100 nM) (both from Sigma-Aldrich; Merck $\mathrm{KGaA}$ ) (sense, 5'-GAUCAUACGUGCGAUCAGA-3' and antisense, 5'-UCUGAUCGCACGUAUGAUC-3') was transfected into the HUVECs for $24 \mathrm{~h}$ using the HiPerFect transfection reagent (Qiagen, Valencia, CA, USA). For the present time-course experiment, the HUVECs were transfected with $50 \mathrm{nM}$ LOX-1 siRNA and the cells were incubated at $37^{\circ} \mathrm{C}$ in $5 \% \mathrm{CO}_{2}$ for set times $(4,8,12,24$ and $48 \mathrm{~h}$ ). For the control
Table I. Primers used for quantitative polymerase chain reaction analysis.

\begin{tabular}{ll}
\hline Gene & \multicolumn{2}{c}{ Primer } \\
\hline GLB1 & F: 5'-TATACTGGCTGGCTAGATCACTG-3' \\
& R: 5'-GGCAAAATTGGTCCCACCTATAA-3' \\
SIRT1 & F: 5'-AAGTTGACTGTGAAGCTGTACG-3' \\
& R: 5'-TGCTACTGGTCTTACTTTGAGGG-3' \\
LOX-1 & F: 5'-TTGCCTGGGATTAGTAGTGACC-3' \\
& R: 5'-GCTTGCTCTTGTGTTAGGAGGT-3' \\
IGF1 & F: 5'-GCTCTTCAGTTCGTGTGTGGA-3' \\
& R: 5'-GCCTCCTTAGATCACAGCTCC-3' \\
IGF1R & F: 5'-AGGATATTGGGCTTTACAACCTG-3' \\
& R: 5'-GAGGTAACAGAGGTCAGCATTTT-3' \\
GAPDH & F: 5'-ACAACTTTGGTATCGTGGAAGG-3' \\
& R: 5'-GCCATCACGCCACAGTTTC-3'
\end{tabular}

GLB1, $\beta$-galactosidase; SIRT1, sirtuin 1; LOX-1, lectin-like oxidized low-density lipoprotein receptor-1; IGF1R, insulin-like growth factor 1 receptor; F, forward; R, reverse.

group, the HUVECs were transfected with the corresponding control-sequence siRNA (i.e. scrambled siRNA). After incubation for $24 \mathrm{~h}$, the cells were harvested and the lysates were subjected to reverse transcription-quantitative polymerase chain reaction (RT-qPCR) analysis to verify the efficacy of knockdown by siRNA.

miRNA transfection. The Ang II-treated HUVECs were first transfected with LOX-1 siRNA $(50 \mathrm{nM})$ for $24 \mathrm{~h}$, and then transfected with different doses of let- $7 \mathrm{~g}(5,10,25$ and $50 \mathrm{nM})$ or control miRNA for $24 \mathrm{~h}$ using the HiPerFect transfection reagent (Qiagen). After incubation for $24 \mathrm{~h}$, the cells were harvested, and the lysates were subjected to RT-qPCR or western blot analysis to verify the efficacy of let-7g transfection.

Cell viability assay. Cells grown in a 96-well plate $\left(10^{4}\right.$ cells/well) were treated with Ang II (10-10 $\left.4 \mathrm{nM}\right)$ for $24 \mathrm{~h}$. WST-1 reagent (Roche, Mannheim, Germany) diluted 1:10 in growth medium was added for the last $2 \mathrm{~h}$ according to the manufacturer's instructions. The amount of viable cells was determined via optical density measurement using a microplate reader at $450 \mathrm{~nm}$, with $600 \mathrm{~nm}$ as a reference wavelength.

$R N A$ isolation and $R T-q P C R$. Total RNA was extracted from the HUVECs using TRIzol ${ }^{\circledR}$ reagent (Invitrogen; Thermo Fisher Scientific, Inc., Waltham, MA, USA), and complementary (c)DNA was produced using $1 \mu \mathrm{g}$ starting mRNA (Applied Biosystems; Thermo Fisher Scientific, Inc.) and random hexamers. Reverse transcription was performed according to the manufacturer's protocol (Applied Biosystems; Thermo Fisher Scientific, Inc.): $25^{\circ} \mathrm{C}$ for $10 \mathrm{~min}, 37^{\circ} \mathrm{C}$ for $120 \mathrm{~min}$ and $85^{\circ} \mathrm{C}$ for $5 \mathrm{~min}$. After the reaction was complete, samples were cooled down to $4^{\circ} \mathrm{C}$. The sequences of the PCR primers are listed in Table I. The relative amount of mRNA 
A

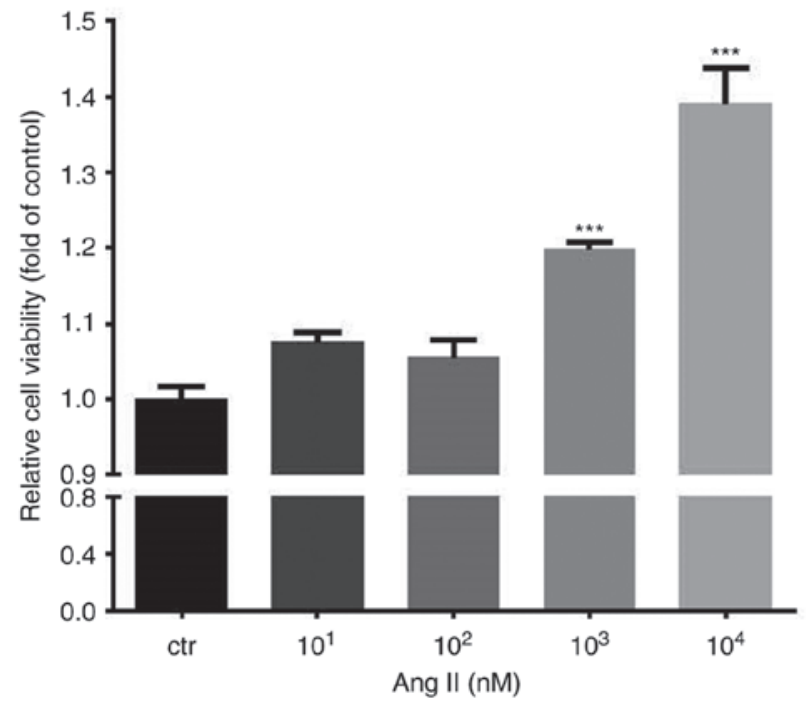

B

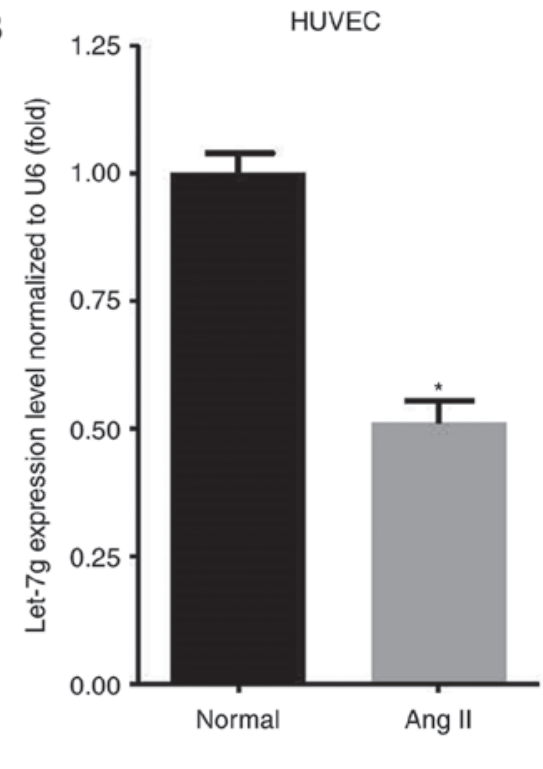

Figure 1. Effect of Ang II on cell viability and let-7 levels in HUVECs. (A) The viability of HUVECs treated with Ang II (10 $10^{4} \mathrm{nM}$ ) for $24 \mathrm{~h}$ was assessed using a WST-1 assay. The viability of treated cells relative to that of the control group is presented. (B) HUVECs treated with Ang II (10 ${ }^{4} \mathrm{nM}$ ) for $24 \mathrm{~h}$ were assessed for let-7g levels. Values are expressed as the mean \pm standard error of the mean. ${ }^{*} \mathrm{P}<0.05$ and ${ }^{* * * *} \mathrm{P}<0.001$ vs. Ctr. Ang II, angiotensin II; HUVECs, human umbilical vein endothelial cells; Ctr, control.

of interest was normalized to GAPDH. PCR was performed using the ABI StepOnePlus ${ }^{\mathrm{TM}}$ Real-Time PCR system and SYBR-Green reagent (Applied Biosystems; Thermo Fisher Scientific, Inc.). PCR was performed in duplicate using $5 \mu \mathrm{l}$ 2X SYBR-Green qPCR Master Mix (Applied Biosystems; Thermo Fisher Scientific, Inc.), $0.2 \mu \mathrm{l}$ primer sets, $1 \mu \mathrm{l}$ cDNA and $3.6 \mu 1$ nucleotide-free $\mathrm{H}_{2} \mathrm{O}$ in a $10-\mu 1$ reaction system. RT-qPCR cycling conditions were as follows: $95^{\circ} \mathrm{C}$ for $20 \mathrm{sec}$, followed by 40 cycles each at $95^{\circ} \mathrm{C}$ for $1 \mathrm{sec}$ and then $60^{\circ} \mathrm{C}$ for $20 \mathrm{sec}$. The relative expression of each mRNA was calculated as the difference of $\mathrm{C}_{\mathrm{q}}$ between the expression of sample and the housekeeping gene GAPDH (28).

Western blot analysis. The HUVECs were harvested using radioimmunoprecipitation assay buffer (Thermo Fisher Scientific, Inc.) supplemented with a protease inhibitor cocktail (Roche). The protein concentrations were determined by using the Pierce BCA Protein assay kit (Thermo Fisher Scientific, Inc.). The proteins were then transferred onto a polyvinylidene difluoride membrane (EMD Millipore, Billerica, MA, USA) and blocked with 5\% non-fat dry milk for $2 \mathrm{~h}$ at room temperature. The membranes were incubated with primary antibodies at $4^{\circ} \mathrm{C}$ for $16 \mathrm{~h}$, including IGF1 (cat. no. ab9572; $0.1 \mu \mathrm{g} / \mathrm{ml}$; Abcam, Cambridge, UK) and GAPDH (cat. no. GTX10011; 1:5,000 dilution; GeneTex, Inc., Irvine, CA, USA). Following three washes in PBST, the membranes were incubated with the secondary rabbit immunoglobulin $\mathrm{G}$ antibody conjugated to horseradish peroxidase (cat. no. GTX213110-01; 1:10,000 dilution; GeneTex, Inc.) at room temperature for $1 \mathrm{~h}$. The enhanced chemiluminescence non-radioactive detection system was used to detect the antibody-protein complexes with the LAS-3000 imaging system (Fujifilm, Tokyo, Japan). Western blot band intensities were quantitatively measured using ImageJ $1.45 \mathrm{~s}$ software (National Institutes of Health, Bethesda, MD, USA).
Senescence-associated $\beta$-galactosidase (SA- $\beta$-gal) assay. The senescent cells were assayed with a SA- $\beta$-gal staining kit (cat. no. K802-250; Biovision, Milpitas, CA, USA) according to the manufacturer's instructions. The HUVECs were washed with PBS, fixed with $4 \%$ paraformaldehyde for $15 \mathrm{~min}$, then washed with PBS and incubated overnight at $37^{\circ} \mathrm{C}$ with a SA- $\beta$-gal staining solution mix. Senescent cells (blue color via SA- $\beta$-gal staining) were observed and counted using a bright-field microscope at x100 magnification, and the percentages of SA- $\beta$-gal positive cells were determined. An independent investigator blinded to the treatment of the samples counted the number of SA- $\beta$-gal-positive cells in five randomly selected high-power fields in each sample.

Statistical analysis. Statistical analysis was performed using Prism software, version 5.0 (GraphPad, Inc., La Jolla, CA, USA). Quantitative data are expressed as the mean \pm standard error of the mean. Student's t-test was used to compare differences between two groups. Differences between multiple groups were analyzed using one-way analysis of variance, followed by Tukey's post hoc multiple comparisons test. A two-sided $\mathrm{P}<0.05$ was considered to indicate a statistically significant difference.

\section{Results}

Ang II increases the viability and decreases the let-7g level of HUVCEs. First, different doses (ranging from 10 to $10^{4} \mathrm{nM}$ ) of Ang II were used to test the effect on the amount of viable HUVECs. The results indicated that Ang II dose-dependently increased the amount of viable HUVECs, with the dose of $10^{4} \mathrm{nM}$ having the most significant effect (Fig. 1A). Therefore, the concentration of $10^{4} \mathrm{nM}$ was used for subsequent experiments. The endogenous let-7g levels were measured prior to and after Ang II treatment. The results indicated that 
A

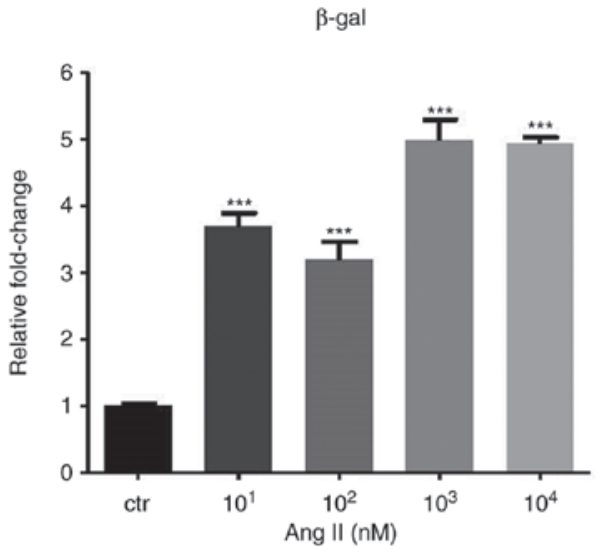

C

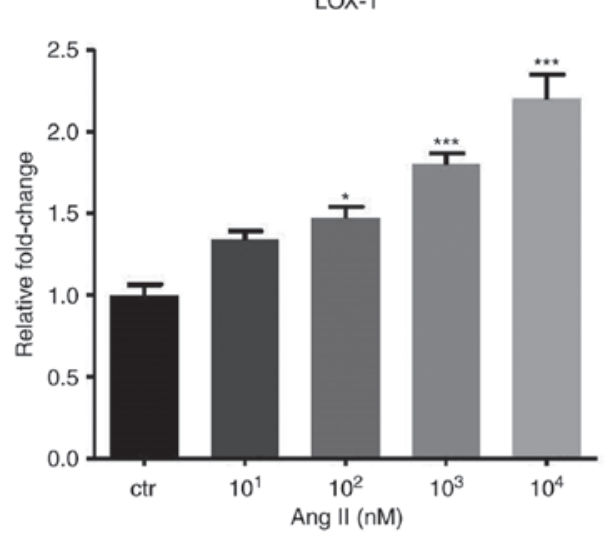

B

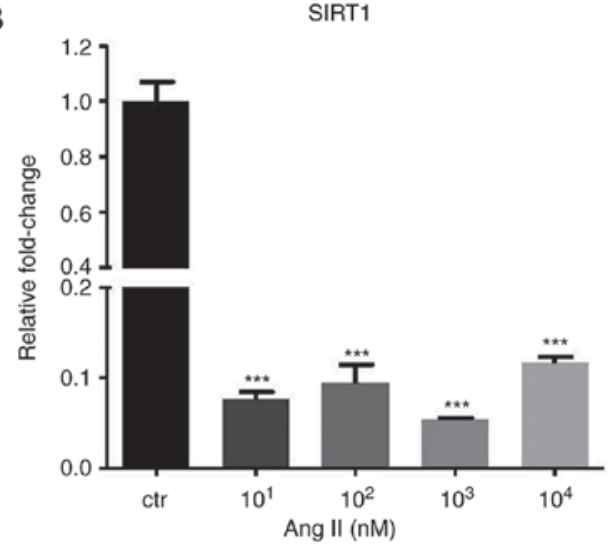

D

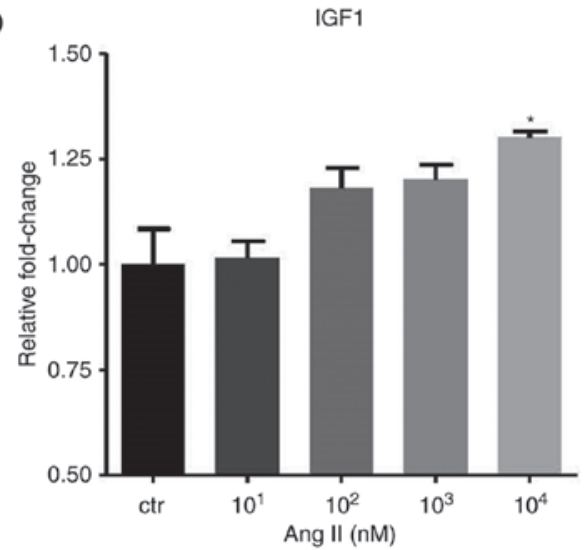

$\mathrm{E}$

IGF1R

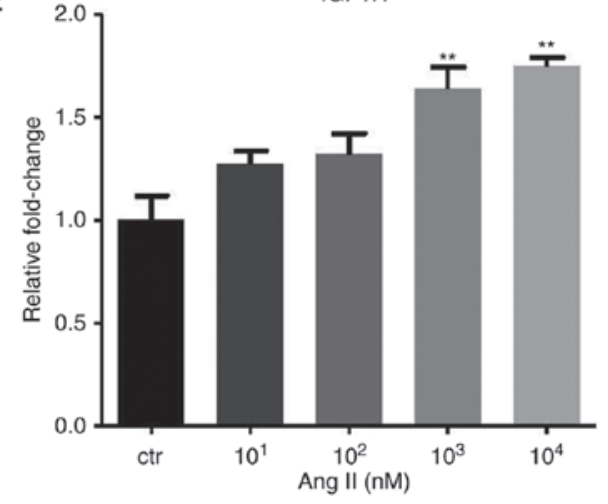

Figure 2. Angiotensin II influences the expression of $\beta$-gal, SIRT1 and IGF1 pathway. The mRNA levels of (A) $\beta$-gal, (B) SIRT1, (C) LOX-1, (D) IGF1 and (E) IGF1R are presented. GAPDH was used as the internal control. Values are expressed as the mean \pm standard error of the mean. ${ }^{*} \mathrm{P}<0.05$, ${ }^{* *} \mathrm{P}<0.01$ and ${ }^{* * * *} \mathrm{P}<0.001$ analyzed by one-way analysis of variance and Tukey's post hoc test. $\beta$-gal, $\beta$-galactosidase; SIRT1, sirtuin 1 ; LOX-1, lectin-like oxidized low-density lipoprotein receptor-1; IGF1R, insulin-like growth factor 1 receptor.

Ang II treatment reduced let-7g levels in HUVECs by $\sim 50 \%$ $(\mathrm{P}=0.001)$ (Fig. 1B).

Ang II affects the expression of $\beta$-galactosidase, SIRT1 and the IGF1 pathway. The GLB1 gene encoding $\beta$-gal and the SIRT1 gene were identified to be positively and negatively associated with cell senescence, respectively. In the Ang II-treated HUVECs, a significant increase of $\beta$-gal $(\mathrm{P}<0.001)$ but a decrease of SIRT1 $(\mathrm{P}<0.001)$ mRNA expression was identified (Fig. 2A and B). In addition, IGF1 signaling was identified to be associated with the aging process. In the HUVECs, Ang II promoted LOX-1 $(\mathrm{P}<0.001)$, IGF1 $(\mathrm{P}<0.05)$ and IGF1 receptor (IGF1R; $\mathrm{P}<0.01$ ) expression (Fig. 2C-E).
Knockdown of LOX-1 in Ang II-treated HUVECs. To explore the effect of let-7g via the LOX-1-independent mechanism, siRNA was employed to knock down LOX-1 expression. The LOX-1-specific siRNA (doses ranging from 25-100 nM) suppressed LOX-1 levels (Fig. 3A). The concentrations of 50 and $100 \mathrm{nM}$ siRNA yielded a similar effect, and therefore, $50 \mathrm{nM}$ siRNA was used in the subsequent experiments unless a specific dose was otherwise mentioned. To further determine the ideal incubation time for siRNA to exert its best inhibitory effect, LOX-1 expression was measured at 5 time-points $(4,8$, 12,24 and $48 \mathrm{~h}$ ) after transfection of $50 \mathrm{nM}$ siRNA into the HUVECs. The results indicated that $90 \%$ inhibition occurred at 24 and 48 h (Fig. 3B). Accordingly, all of the subsequent 
A

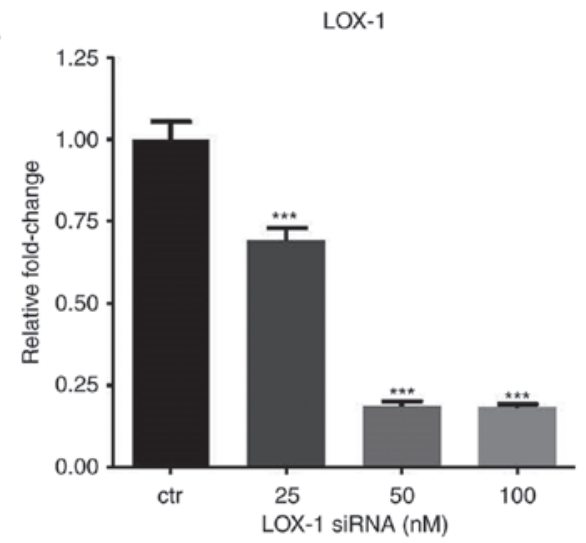

C

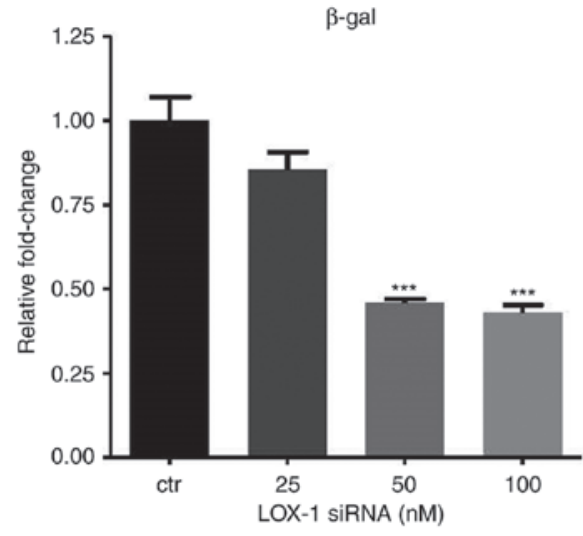

E

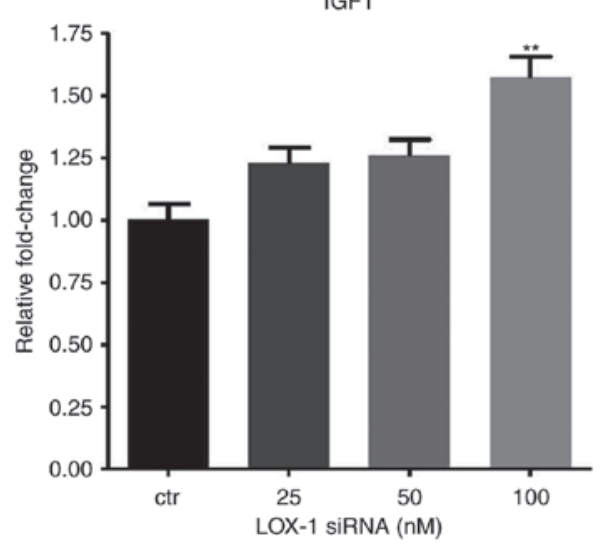

B

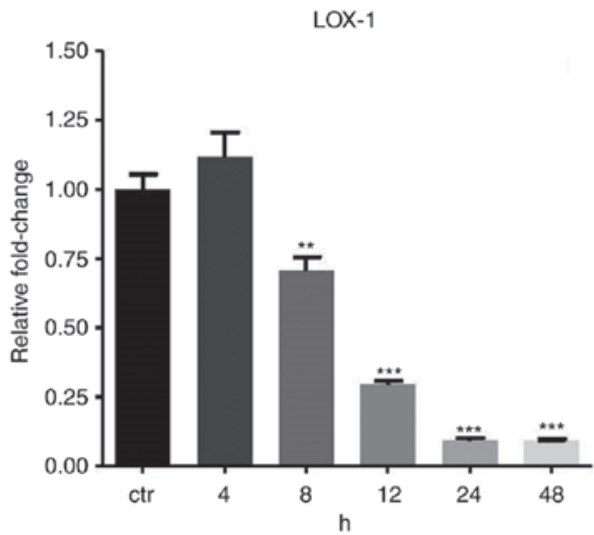

D

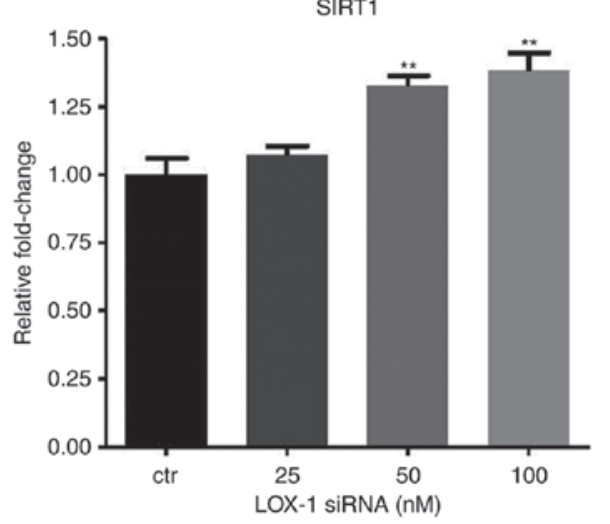

$\mathrm{F}$

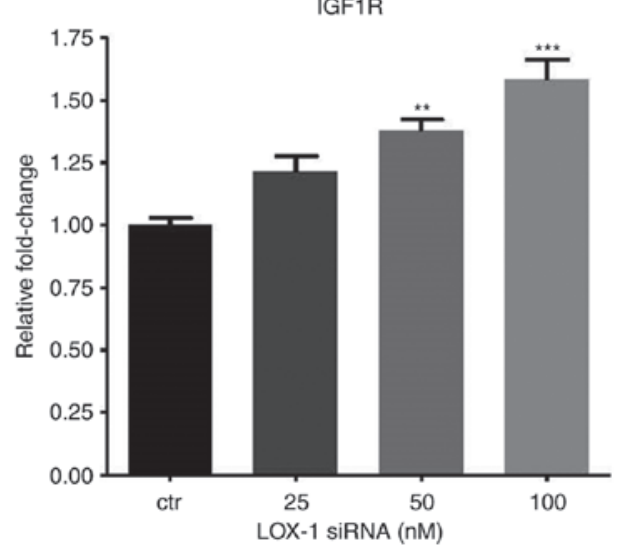

Figure 3. Effects of LOX-1 silencing on aging-associated gene expression in Ang II-treated human umbilical vein endothelial cells. The cells were first treated with Ang II $\left(10^{4} \mathrm{nM}\right)$ for $24 \mathrm{~h}$, and then transfected with LOX-1 siRNA for another $24 \mathrm{~h}$. (A) LOX-1 mRNA expression levels were suppressed after transfection of LOX-1 siRNA (25-100 nM). (B) To determine the incubation time with the optimal inhibitory effect, LOX-1 mRNA levels were measured at different time-points after transfection with LOX-1 siRNA (50 nM). (C-F) The mRNA levels of (C) $\beta$-gal, (D) SIRT1, (E) IGF1 and (F) IGF1R were affected by LOX-1 knockdown. Values are expressed as the mean \pm standard error of the mean. ${ }^{*} \mathrm{P}<0.05,{ }^{* *} \mathrm{P}<0.01$ and ${ }^{* * *} \mathrm{P}<0.001$ analyzed by one-way analysis of variance and Tukey's post hoc test. $\beta$-gal, $\beta$-galactosidase; SIRT1, sirtuin 1; LOX-1, lectin-like oxidized low-density lipoprotein receptor-1; IGF1R, insulin-like growth factor 1 receptor; siRNA, small interfering RNA; Ang II, angiotensin II.

results were obtained at $24 \mathrm{~h}$ after siRNA transfection. When LOX-1 expression was knocked down, $\beta$-gal expression also decreased in a dose-dependent manner in the Ang II-treated HUVECs (Fig. 3C). Furthermore, SIRT1, IGF1 and IGF1R levels in the Ang II-treated HUVECs increased along with the elevation of the dose of LOX-1-siRNA (Fig. 3D-F).

Let-7g exerts its anti-aging effect via a LOX-1-independent mechanism. Since a previous study by our group reported that let-7g has an anti-senescence effect on ECs (12), the present study assessed whether let-7g also affects aging-associated gene expression and pathways in a LOX-1-independent manner. In the Ang II-treated and LOX-1-siRNA-transfected HUVECs, transfection of exogenous let-7g reduced mRNA expression of IGF1, IGF1R and $\beta$-gal (Fig. 4A-C), while it increased SIRT1 mRNA expression (Fig. 4D). Finally, HUVECs that had been incubated under different conditions were subjected to SA- $\beta$-gal staining (Fig. 5). The results indicated that the amount of SA- $\beta$-gal-positive HUVECs was markedly increased by Ang II (Fig. 5A and B), while transfection of LOX-1 siRNA partially abolished the effect of Ang II (Fig. 5C). The SA- $\beta$-gal staining result further supported the notion that let- $7 \mathrm{~g}$ reduces 

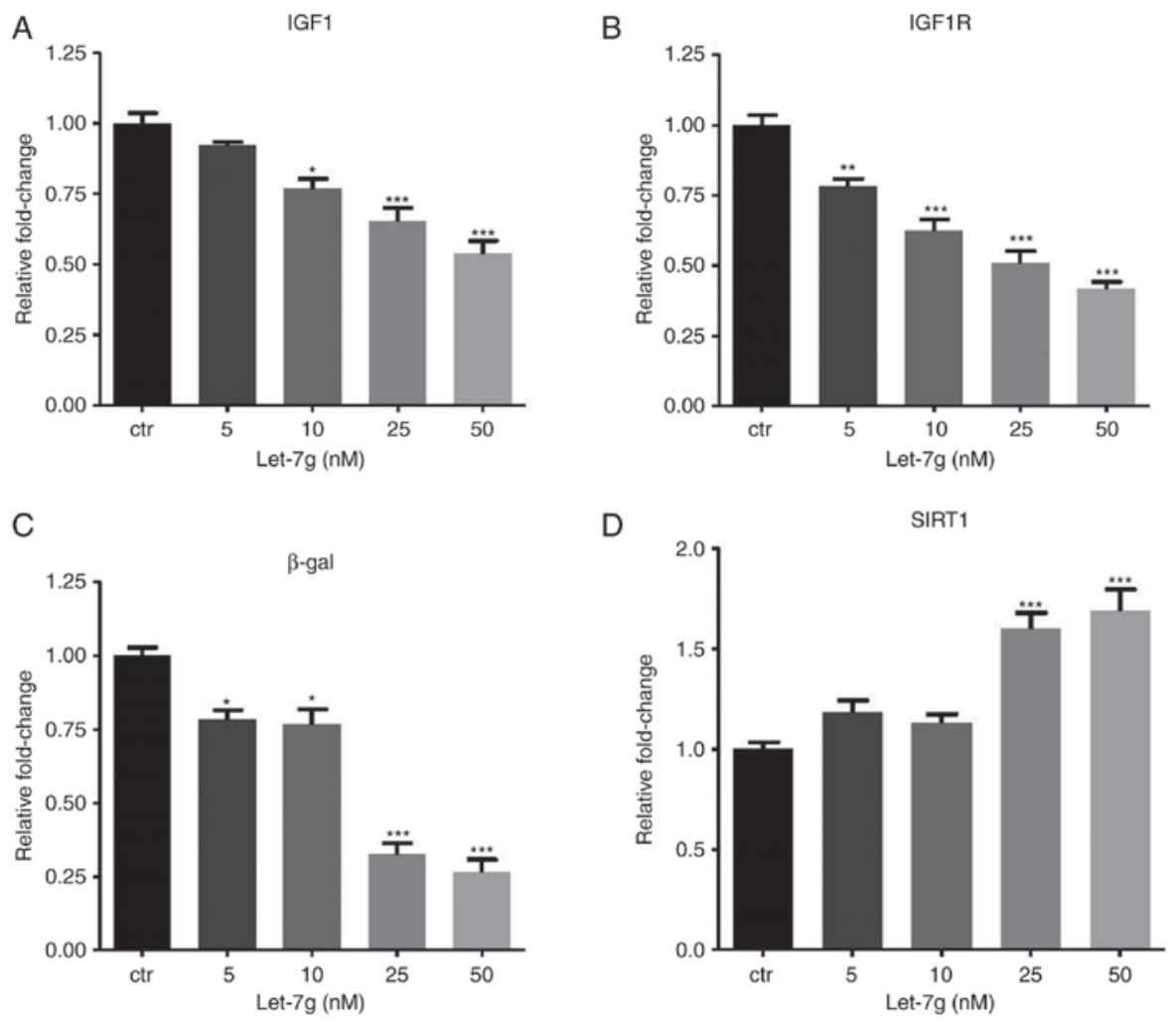

Figure 4. Let-7g affects aging-associated gene expression via a LOX-1-independent mechanism. Human umbilical vein endothelial cells were treated with Ang II $\left(10^{4} \mathrm{nM}\right)$ for $24 \mathrm{~h}$, followed by transfection with $50 \mathrm{nM}$ small interfering RNA targeting LOX-1 for another $24 \mathrm{~h}$. Subsequently, the cells were transfected with ctr microRNA or let-7g $(5,10,25$ and $50 \mathrm{nM}$ ) or for $24 \mathrm{~h}$. The mRNA levels of (A) IGF1, (B) IGF1R, (C) $\beta$-gal and (D) SIRT1 were measured by reverse transcription-quantitative polymerase chain reaction analysis. Values are expressed as the mean \pm standard error of the mean. ${ }^{*} \mathrm{P}<0.05,{ }^{* *} \mathrm{P}<0.01$ and ${ }^{* * * *} \mathrm{P}<0.001$ analyzed by one-way analysis of variance and Tukey's post hoc test. $\beta$-gal, $\beta$-galactosidase; SIRT1, sirtuin 1 ; LOX-1, lectin-like oxidized low-density lipoprotein receptor-1; IGF1R, insulin-like growth factor 1 receptor; Ang II, angiotensin II; ctr, control.

senescence in Ang II-treated and LOX-1-siRNA-transfected HUVECs (Fig. 5D and E). Previous studies have demonstrated that let-7g suppresses the protein levels of IGF1R $(29,30)$ and increases the amount of SIRT1 protein (12). Therefore, the present study only assessed the inhibitory effect of let-7g on IGF1 protein levels. When cells were treated with Ang II, western blot analysis of IGF1 provided results that were consistent with those on the mRNA levels of IGF1 (Fig. 4A).

\section{Discussion}

Ang II has been demonstrated to be an important signaling molecule involved in atherogenic stimuli, and has been indicated to promote aging and cellular senescence (31). Ang II has been revealed to induce cardiac fibrosis and downregulation of miRNA-29 expression (32). miRNA-29 induces cellular senescence via increasing $p 53$, upregulating $\beta$-gal (33) and suppressing SIRT1 expression (34). In the present study, it was demonstrated that Ang II attenuated let-7g expression and induced senescence in ECs. An increase of let-7g significantly upregulated SIRT1 expression and decreased $\beta$-gal expression and cellular senescence. Therefore, Ang II may increase senescence-producing miRNA and suppress anti-senescence miRNA. In Ang II-treated ECs, the expression of aging-associated markers, including $\beta$-gal, IGF1, IGF1R and LOX-1, was increased. Conversely, Ang II decreased the expression of the anti-aging marker SIRT1. In addition, LOX-1 was identified to promote the aging process, as indicated by an increase of $\beta$-gal. As the purpose of the present study was to determine the effect of let-7g on Ang II-induced senescence, all the cells were first treated with Ang II prior to further experiments. Therefore, the present study does not have data on the effect of let-7g on cells without Ang II treatment, which is a limitation. Since a previous study by our group has indicated that let-7g directly suppresses LOX-1 (25), the present study examined whether let-7g exerts a LOX-1-independent anti-aging effect. In Ang II-treated HUVECs with LOX-1 knockdown, let-7g still reduced the expression of IGF1, IGF1R and $\beta$-gal but increased the SIRT1 expression. Furthermore, using the SA- $\beta$-gal staining as an aging indicator, the anti-aging effect of let-7g via a LOX-1-independent mechanism was confirmed. Taken together, the present results suggest that anti-aging effect of let-7g on ECs proceeds via a LOX-1-dependent and a LOX-1-independent mechanism. Along with the previous study by our group on the effect of let-7g on LOX-1 (25), its anti-aging effect determined in the present study was summarized in a hypothetical scheme (Fig. 6). The right side of Fig. 6 illustrates that the anti-senescence effect of let-7g may be mediated by suppressing the oxLDL-LOX-1 pathway, while the left side indicates that let-7g may also suppress IGF1 signaling to exert the anti-senescence effect.

LOX-1 promotes cell senescence. While LOX-1 is almost undetectable under physiological conditions, it is upregulated after exposure to several proinflammatory and proatherogenic stimuli (35). A previous study by our group confirmed that let-7g reduces EC senescence through increasing SIRT-1 

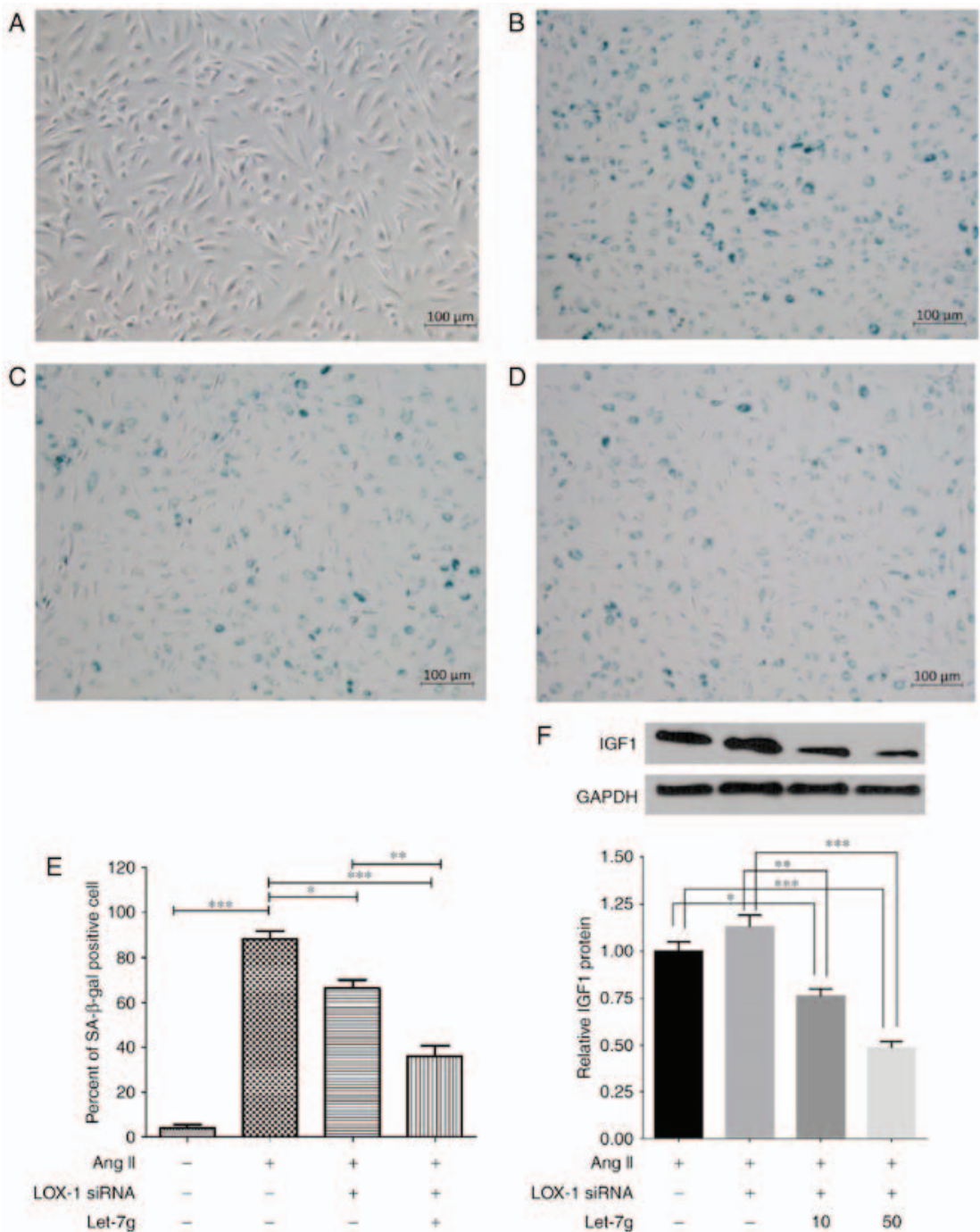

Figure 5. Let-7g suppresses Ang II-induced HUVEC senescence and IGF protein levels. (A-D) Images of SA- $\beta$-gal staining of HUVECs (scale bar, $100 \mu \mathrm{m}$ ). (A) HUVECs (normal), (B) HUVECs treated with Ang II (104 nM), (C) HUVECs treated with Ang II $\left(10^{4} \mathrm{nM}\right)$ and then transfected with LOX-1 siRNA $(50 \mathrm{nM})$, (D) HUVECs treated with Ang II (50 nM), followed by LOX-1 siRNA (50 nM) and then by let-7g $(50 \mathrm{nM})$. Each individual incubation lasted for $24 \mathrm{~h}$. (E) Percentage of SA- $\beta$-gal-positive cells. The cells from 5 randomly selected microscopic fields of view were counted. (F) Western blot results indicated that let-7g dose-dependently inhibited IGF1 protein expression via a LOX-1-independent pathway. Values are expressed as the mean \pm standard error of the mean ( $\mathrm{n}=3$ for each group). ${ }^{*} \mathrm{P}<0.05,{ }^{* *} \mathrm{P}<0.01$ and ${ }^{* * *} \mathrm{P}<0.001$ analyzed by one-way analysis of variance and Tukey's post hoc test. LOX-1, lectin-like oxidized-low-density lipoprotein receptor-1; IGF1, insulin-like growth factor 1; HUVECs, human umbilical vein endothelial cells; SA- $\beta$-gal, senescence-associated $\beta$-galactosidase; siRNA, small interfering RNA; Ang II, angiotensin II.

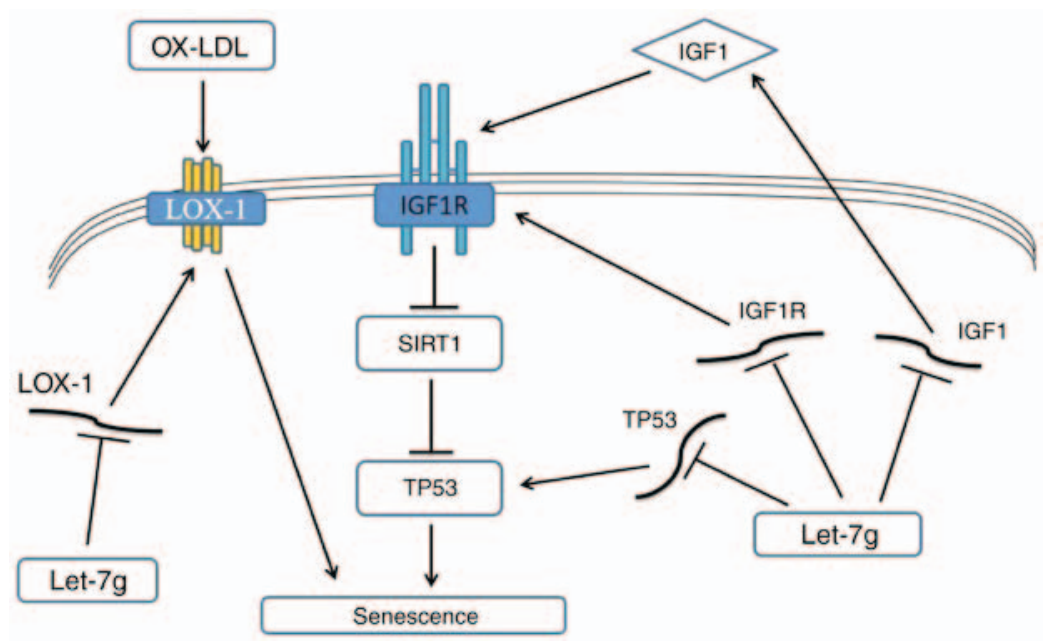

Figure 6. Hypothetic scheme illustrating multiple regulatory pathways of the anti-aging effects of let-7g in human umbilical vein endothelial cells. SIRT1, sirtuin 1; LOX-1, lectin-like ox-LDL receptor-1; ox-LDL, oxidized low-density lipoprotein; IGF1R, insulin-like growth factor 1 receptor; TP53, tumor protein 53. 
protein, but did not assess whether the anti-aging effect of let-7g is mediated through LOX-1 (12). The present study was specifically designed to assess the anti-aging effect of let-7g when LOX-1 was not present. The current findings imply that let-7g exerts an anti-aging effect regardless of the presence or absence of LOX-1, which further suggests that let- $7 \mathrm{~g}$ possesses an anti-aging function via multiple mechanisms.

Ang II increased the levels of LOX-1, IGF1 and IGF1R in HUVECs or microglial cells $(36,37)$. IGF signaling has a significant role in ECs by promoting migration, tube formation and production of the vasodilator nitric oxide. The over-activation of IGF signaling, however, may suppress SIRT1 expression, contributing to the aging process. Reduced IGF signaling has also been associated with increased longevity (38). In fact, the insulin pathway coordinates growth, development, metabolic homoeostasis and stress resistance, all of which affect the lifespan.

The let-7 family has a central role in nutrient homeostasis and insulin resistance $(39,40)$. Previous studies have indicated that IGF1R is a target of let-7g in mouse granulosa cells and colon cancer cells $(29,30)$. The present study further indicated that let- $7 \mathrm{~g}$ reduces IGF1 expression in the presence of Ang II stimulation, demonstrating a profound effect of let- $7 \mathrm{~g}$ on the IGF1 signaling pathway.

In conclusion, the present study provided novel insight into the anti-aging effect of let-7g on ECs, which occurs regardless of the presence of LOX-1. The present results also suggest that let-7g has direct effects on multiple targets of the IGF signaling pathway. Given that healthy and young ECs are crucial for the cardiovascular system, blood brain barrier, and other systemic functions, maintenance of sufficient let-7g levels may be an important strategy to reduce the senescent process.

\section{Acknowledgements}

The present study was supported by grants from the Ministry of Science and Technology (MOST) of Taiwan, R.O.C. (grant nos. MOST105-2314-B-039-050, MOST103-2314-B-037-026-MY3 and MOST104-2745-B-037-001), Academia Sinica Taiwan BiobankStrokeBiosignatureProject(grantno.BM10601010036) and a grant from the National Health Research Institutes of Taiwan, R.O.C. (grant no. NHRI-EX106-10605PI).

\section{Competing interests}

The authors declare that they have no competing interests.

\section{References}

1. Campisi J: Aging, cellular senescence, and cancer. Annu Rev Physiol 75: 685-705, 2013.

2. Félétou M and Vanhoutte PM: Endothelial dysfunction: A multifaceted disorder (The Wiggers Award Lecture). Am J Physiol Heart Circ Physiol 291: H985-H1002, 2006.

3. Xu S, Ogura S, Chen J, Little PJ, Moss J and Liu P: LOX-1 in atherosclerosis: Biological functions and pharmacological modifiers. Cell Mol Life Sci 70: 2859-2872, 2013.

4. Wang X, Khaidakov M, Ding Z, Dai Y, Mercanti F and Mehta JL: LOX-1 in the maintenance of cytoskeleton and proliferation in senescent cardiac fibroblasts. J Mol Cell Cardiol 60: 184-190, 2013.

5. Mehta PK and Griendling KK: Angiotensin II cell signaling: Physiological and pathological effects in the cardiovascular system. Am J Physiol Cell Physiol 292: C82-C97, 2007.
6. Kambayashi Y, Bardhan S, Takahashi K, Tsuzuki S, Inui H, Hamakubo $\mathrm{T}$ and Inagami T: Molecular cloning of a novel angiotensin II receptor isoform involved in phosphotyrosine phosphatase inhibition. J Biol Chem 268: 24543-24546, 1993.

7. Sasaki K, Yamano Y, Bardhan S, Iwai N, Murray JJ, Hasegawa M, Matsuda Y and Inagami T: Cloning and expression of a complementary DNA encoding a bovine adrenal angiotensin II type-1 receptor. Nature 351: 230-233, 1991.

8. Min LJ, Mogi M, Iwai M and Horiuchi M: Signaling mechanisms of angiotensin II in regulating vascular senescence. Ageing Res Rev 8: 113-121, 2009.

9. Kunieda T, Minamino T, Nishi J, Tateno K, Oyama T, Katsuno T, Miyauchi H, Orimo M, Okada S, Takamura M, et al: Angiotensin II induces premature senescence of vascular smooth muscle cells and accelerates the development of atherosclerosis via a p21-dependent pathway. Circulation 114: 953-960, 2006.

10. Li DY, Zhang YC, Philips MI, Sawamura T and Mehta JL: Upregulation of endothelial receptor for oxidized low-density lipoprotein (LOX-1) in cultured human coronary artery endothelial cells by angiotensin II type 1 receptor activation. Circ Res 84: 1043-1049, 1999.

11. Feige JN and Auwerx J: Transcriptional targets of sirtuins in the coordination of mammalian physiology. Curr Opin Cell Biol 20: 303-309, 2008

12. Liao YC, Wang YS, Guo YC, Lin WL, Chang MH and Juo SH: Let-7g improves multiple endothelial functions through targeting transforming growth factor-beta and SIRT-1 signaling. J Am Coll Cardiol 63: 1685-1694, 2014.

13. Gorenne I, Kumar S, Gray K, Figg N, Yu H, Mercer J and Bennett M: Vascular smooth muscle cell sirtuin 1 protects against DNA damage and inhibits atherosclerosis. Circulation 127: 386-396, 2013

14. Stein S, Lohmann C, Schäfer N, Hofmann J, Rohrer L, Besler C, Rothgiesser KM, Becher B, Hottiger MO, Borén J, et al: SIRT1 decreases Lox-1-mediated foam cell formation in atherogenesis. Eur Heart J 31: 2301-2309, 2010.

15. Zhang QJ, Wang Z, Chen HZ, Zhou S, Zheng W, Liu G, Wei YS, Cai H, Liu DP and Liang CC: Endothelium-specific overexpression of class III deacetylase SIRT1 decreases atherosclerosis in apolipoprotein E-deficient mice. Cardiovasc Res 80: 191-199, 2008.

16. Kenyon C: A conserved regulatory system for aging. Cell 105: $165-168,2001$.

17. Longo VD and Finch CE: Evolutionary medicine: From dwarf model systems to healthy centenarians? Science 299: 1342-1346, 2003.

18. Lai CH, Ho TJ, Kuo WW, Day CH, Pai PY, Chung LC, Liao PH, Lin FH, Wu ET and Huang CY: Exercise training enhanced SIRT1 longevity signaling replaces the IGF1 survival pathway to attenuate aging-induced rat heart apoptosis. Age (Dordr) 36: 9706, 2014.

19. Brunet A, Sweeney LB, Sturgill JF, Chua KF, Greer PL, Lin Y, Tran H, Ross SE, Mostoslavsky R, Cohen HY, et al: Stress-dependent regulation of FOXO transcription factors by the SIRT1 deacetylase. Science 303: 2011-2015, 2004.

20. Cohen HY, Miller C, Bitterman KJ, Wall NR, Hekking B, Kessler B, Howitz KT, Gorospe M, de Cabo R and Sinclair DA: Calorie restriction promotes mammalian cell survival by inducing the SIRT1 deacetylase. Science 305: 390-392, 2004.

21. Tissenbaum HA and Guarente L: Increased dosage of a sir- 2 gene extends lifespan in Caenorhabditis elegans. Nature 410: 227-230, 2001.

22. Bushati N and Cohen SM: microRNA functions. Annu Rev Cell Dev Biol 23: 175-205, 2007.

23. Bao MH, Feng X, Zhang YW, Lou XY, Cheng Y and Zhou HH: Let-7 in cardiovascular diseases, heart development and cardiovascular differentiation from stem cells. Int J Mol Sci 14: 23086-23102, 2013.

24. Chiu SC, Chung HY, Cho DY, Chan TM, Liu MC, Huang HM, Li TY, Lin JY, Chou PC, Fu RH, et al: Therapeutic potential of microRNA let-7: Tumor suppression or impeding normal stemness. Cell Transplant 23: 459-469, 2014.

25. Chen KC, Hsieh IC, His E, Wang YS, Dai CY, Chou WW and Juo SH: Negative feedback regulation between microRNA let-7g and the oxLDL receptor LOX-1. J Cell Sci 124: 4115-4124, 2011.

26. Hsu PY, His E, Wang TM, Lin RT, Liao YC and Juo SH: MicroRNA let-7g possesses a therapeutic potential for peripheral artery disease. J Cell Mol Med 21: 519-529, 2017.

27. Yang LL, Li DY, Zhang YB, Zhu MY, Chen D and Xu TD: Salvianolic acid A inhibits angiotensin II-induced proliferation of human umbilical vein endothelial cells by attenuating the production of ROS. Acta Pharmacol Sin 33: 41-48, 2012. 
28. Schmittgen TD and Livak KJ: Analyzing real-time PCR data by the comparative C(T) method. Nat Protoc 3: 1101-1108, 2008.

29. Choo KB, Soon YL, Nguyen PN, Hiew MS and Huang CJ: MicroRNA-5p and $-3 p$ co-expression and cross-targeting in colon cancer cells. J Biomed Sci 21: 95, 2014.

30. Zhou J, Yao W, Liu K, Wen Q, Wu W, Liu H and Li Q: MicroRNA let-7g regulates mouse granulosa cell autophagy by targeting insulin-like growth factor 1 receptor. Int J Biochem Cell Biol 78 : 130-140, 2016.

31. Shan H, Bai X and Chen X: Angiotensin II induces endothelial cell senescence via the activation of mitogen-activated protein kinases. Cell Biochem Funct 26: 459-466, 2008.

32. Zhang Y, Huang XR, Wei LH, Chung AC, Yu CM and Lan HY: miR-29b as a therapeutic agent for angiotensin II-induced cardiac fibrosis by targeting TGF- $\beta / \operatorname{Smad} 3$ signaling. Mol Ther 22: 974-985, 2014

33. Hu Z, Klein JD, Mitch WE, Zhang L, Martinez I and Wang XH: MicroRNA-29 induces cellular senescence in aging muscle through multiple signaling pathways. Aging (Albany NY) 6: 160-175, 2014.

34. Xu Z,Zhang L, Fei X, Yi X, Li W and Wang Q: The miR-29b-Sirt1 axis regulates self-renewal of mouse embryonic stem cells in response to reactive oxygen species. Cell Signal 26: 1500-1505, 2014.

35. Pirillo A, Norata GD and Catapano AL: LOX-1, OxLDL, and atherosclerosis. Mediators Inflamm 2013: 152786, 2013.
36. Morawietz H, Rueckschloss U, Niemann B, Duerrschmidt N, Galle J, Hakim K, Zerkowski HR, Sawamura T and Holtz J: Angiotensin II induces LOX-1, the human endothelial receptor for oxidized low-density lipoprotein. Circulation 100: 899-902, 1999.

37. Rodriguez-Perez AI, Borrajo A, Diaz-Ruiz C, Garrido-Gil P and Labandeira-Garcia JL: Crosstalk between insulin-like growth factor-1 and angiotensin-II in dopaminergic neurons and glial cells: Role in neuroinflammation and aging. Oncotarget 7: 30049-30067, 2016.

38. Suh Y, Atzmon G, Cho MO, Hwang D, Liu B, Leahy DJ, Barzilai $\mathrm{N}$ and Cohen P: Functionally significant insulin-like growth factor I receptor mutations in centenarians. Proc Natl Acad Sci USA 105: 3438-3442, 2008.

39. Dubinsky AN, Dastidar SG, Hsu CL, Zahra R, Djakovic SN, Duarte S, Esau CC, Spencer B, Ashe TD, Fischer KM, et al: Let-7 coordinately suppresses components of the amino acid sensing pathway to repress mTORC1 and induce autophagy. Cell Metab 20: 626-638, 2014.

40. Zhu H, Shyh-Chang N, Segrè AV, Shinoda G, Shah SP, Einhorn WS, Takeuchi A, Engreitz JM, Hagan JP, Kharas MG, et al: The Lin28/let-7 axis regulates glucose metabolism. Cell 147: 81-94, 2011. 